\title{
PERBAIKAN PEMBELAJARAN DENGAN MENGGUNAKAN BUPENA PADA PERCOBAAN TEMA BAGIAN TUMBUH-TUMBUHAN DAN FUNGSINYA DI KELAS IV SD NEGERI 068007 MEDAN TUNTUNGAN
}

\author{
Hotma Tiolina Siregar, Taty Sukanti Halawa \\ Surel : tiolinahotma@gmail.com
}

\begin{abstract}
This study aims to improve science learning by using BUPENA which has been developed in the Experimental Theme of Plants and Their Functions. The subjects in this study were students of SD NEGERI 068007 Medan Tuntungan TP.2020-2021, with the object of improving the lesson plans and the use of Bupena. This research uses Classroom Action Research with 2 cycles of improvement. The results showed that there was an improvement in learning, this can be seen from the suitability of the lesson plans that were prepared with the aim and the increase in the score on the teaching simulation video observation instrument in cycle 1 learning obtained a score of 90, after conducting learning simulations and conducting experiments the score increased by 96. The results of the study obtained that the N-Gain score of Learning Improvement in cycle 1 was 90 and 96 in cycle 2. Thus it can be concluded that there was an improvement in science learning using Bupena in the experimental theme Part of plants and their functions in Class IV SD 068007 Medan Tuntungan TP.2020 -2021.
\end{abstract}

Keywords: Right, Bupena, Temptation

\begin{abstract}
ABSTRAK
Penelitian ini bertujuan untuk memperbaiki Pembelajaran IPA dengan menggunakan BUPENA yang telah dikembangkan pada percobaan Tema Tumbuh-Tumbuhan dan Fungsinya. Subjek dalam Penelitian ini Siswa SD NEGERI 068007 Medan Tuntungan TP.2020-2021, dengan objek perbaikan RPP dan Penggunaan Bupena. Penelitian ini menggunakan Penelitian Tindakan Kelas dengan 2 siklus Perbaikan. Hasil Penelitian menunjukkan bahwa terdapat perbaikan pembelajaran, hal ini terlihat dari kesesuaian RPP yang disusun dengan tujuan serta kenaikan perolehan skor pada instrumen pengamatan vidio simulasi mengajar pada siklus 1 pembelajaran memperoleh skor sebesar 90, setelah melakukan simulasi pembelajaran dan melakukan percobaan mengalami kenaikan skor sebesar 96. Hasil penelitian diperoleh N-Gain score Perbaikan Pembelajaran siklus 1 sebesar 90 dan 96 pada siklus 2. Dengan demikian dapat disimpulkan bahwa terjadi perbaikan pembelajaran IPA dengan menggunakan Bupena pada percobaan tema Bagian tumbuh-tumbuhan dan Fungsinya di Kelas IV SD 068007 Medan Tuntungan TP.2020-2021.
\end{abstract}

Kata Kunci: Perbaikan, Bupena, Percobaan 


\section{PENDAHULUAN}

Pendidikan

memegang

peranan yang sangat penting dalam mencetak dan membangun generasi berkualitas.

Penyelenggaraan pendidikan yang berkualitas merupakan investasi jangka panjang". Pada saat sekarang ini, kurikulum 2013 merupakan upaya pemerintah dalam memperbaiki sistem pendidikan di Indonesia. Dalam standar isi kurikulum 2013 dijelaskan bahwa dalam mata pelajaran IPA peserta didik diharapkan dapat menunjukkan sikap, logis, kritis, analitis, kreatif, cermat dan teliti, bertanggung jawab, responsif, dan tidak mudah menyerah dalam memecahkan masalah. Pendidikan IPA di Sekolah Dasar bertujuan agar siswa menguasai pengetahuan, konsep, prinsip, proses penemuan, serta memiliki sikap ilmiah, yang akan bermanfaat bagi siswa dalam mempelajari diri dan alam sekitar. Pendidikan IPA menekankan pada pemberian pengalaman langsung untuk mencari tahu dan berbuat sehingga mampu menjelajahi dan memahami alam sekitar secara ilmiah.

Agar tujuan pendidikan bisa tercapai dengan maksimal tentunya guru sebagai pendidik harus mampu merancang proses pembelajaran sedemikian rupa sehingga pelaksanaan kegiatan belajar mengajar dapat berlangsung dengan baik dan akhirnya tujuan pembelajaran sesuai dengan yang sudah ditetapkan dapat tercapai. Halhal yang penting direncanakan guru dengan baik antara lain, metode (cara mengajar), media (alat peraga), proses, evaluasi dan yang paling penting adalah tujuan pembelajaran. Keseluruhan unsur yang harus direncanakan guru dengan baik tersebut mengacu kepada pencapaian tujuan. Dengan tercapainya tujuan pembelajaran maka tercapai pula kompetensi yang diharapkan diperoleh oleh peserta didik.

Pembelajaran Ilmu Pengetahuan Alam (IPA) di SD merupakan wahana untuk membekali siswa dengan pengetahuan keterampilan, dan sikap yang diperlukan untuk melanjutkan pendidikan dan untuk menyesuaikan diri dengan perubahan- perubahan di sekelilingnya. Pembelajaran IPA sejak dini akan menghasilkan generasi dewasa yang melihat sains yang dapat menghadapi tantangan hidup dalam dunia yang makin kompetitif, sehingga mereka mampu turut serta memilih dan mengolah informasi untuk digunakan dalam mengambilkeputusan. Pembelajaran IPA sebenarnya memrupakan mata pelajaran yang sangat dekat dengan aktifitas manusia sehari-hari, sehingga dalam pembelajarannyapun seyogyanya dapat mendekatkan siswa dengan lingkungan sekitarnya bukan sebaliknya membingungkan siswa.

Untuk membantu guru mengimplementasikan kurikulum 2013, dikembangkanlah BUPENA (Buku Penilaian Autentik). Yang berisi rangkaian proses pembelajaran yang disajikan dalam urutan yang sesuai dengan buku teks tematik 
pemerintah dengan mengakomodasi: 1.Pendalaman materi, berisi materi tambahan untuk mempertajam pemahaman siswa terhadap materi yang sedang dipelajari, 2.Kegiatan, disajikan bervariasi yang meliputi kegiatan kinerja praktik, kinerja produk, proyek, atau portofolio. Disajikan pula contoh kegiatan terpilih yang dapat disajikan instrument penilaian keterampilan dan sikap, 3.Ayo Berlatih, berisi soalsoal latihan untuk mengakomodasi penilaian aspek pengetahuan, 4.Tes Tertulis, berisi soal-soal pengetahuan yang disajikan sebagai contoh instrument penilaian pengetahuan, 5.Penugasan, berisi tugas untuk siswa yang dapat disajikan sebagai komponen instrument penilaian pengetahuan.

\section{METODE PENELITIAN}

Jenis Penelitian yang digunakan adalah penelitian Tindakan Kelas (PTK) diawali dengan langkah-langkah penelitian tindakan kelas diantaranya yaitu: a. Perencanaan (Planning), b. Observasi (Observe), c. Refleksi (Reflecting). Prosedur perbaikan pembelajaran dalama pelaksanaan teridiri dari 4 Tahap yaitu: Perencanaan, Pelaksanaan Tindakan, Pengamatan, dan Refleksi.

\section{HASIL PENELITIAN PEMBAHASAN}

Siklus I

Adapun hasil pengukuran keberhasilan tindakan perbaikan pembelajaran siklus 1 yaitu penilaian terhadap RPP dan video simulasi perbaikan pembelajaran siklus 1 telah dilakukan oleh Validator dengan menggunakan instrumen APS- 1 dan APS- 2. Hasil review dan refleksi pada RPP dan Video untuk siklus 1 yaitu: Alat Penilaian Simulasi 1 (APS-1) Lembar Penilaian Simulasi Merencanakan Perbaikan Pembelajaran Percobaan Petunjuk: Baca dengan cermat rencana perbaikan pembelajaran yang akan digunakan oleh guru / mahasiswa ketika mengajar. Kemudian, nilailah semua aspek yang terdapat dalam rencana tersebut dengan menggunakan butir penilaian di bawah ini.

Alat Penilaian Simulasi 2 (APS-2)-Lembar Penilaian Simulasi Melaksanakan Perbaikan Pembelajaran Percobaan Petunjuk: Amatilah dengan cermat video pembelajaran. Pusatkanlah perhatian Anda pada kemampuan guru dalam mengelola pembelajaran serta dampaknya pada diri siswa. Nilailah kemampuan guru tersebut dengan menggunakan butir-butir penilaian berikut. Penggabungan APS $1+$ APS $2=(1 \times$ APS $1+2 \times$ APS 2$) / 3$ $\mathrm{x} \quad 100 / 5$ Skor Perolehan penggabungan antara teori dan praktek $=(1 \times 4.5+2 \times 4.5) / 3 \times$ $100 / 5=90$

Hasil pada pengukuran keberhasilan tindakan perbaikan pembelajaran percobaan siklus 1 , yakni melalui penilaian RPP perbaikan pembelajaran siklus 1 dan video praktek simulasi pembelajaran 
Hotma Tiolina Siregar,Taty Sukanti Halawa : Perbaikan Pembelajaran ...

praktikum siklus 1 telah dilakukan oleh Validator menggunakan instrumen APS-1 dan APS-2. Hasil penilaian terhadap RPP siklus 1 melalui instrumen APS-1 diperoleh skor sebesar 4,5 dan hasil penilaian terhadap video simulasi pembelajaran praktikum siklus 1 melalui instrumen APS-2 diperoleh skor sebesar 4,5. Kemudian untuk penggabungan APS$1+$ APS-2 yang dihitung melalui rumus $(1 \times$ APS PKP1 $+2 \times$ APS PKP2 $) / 3 \times 100 / 5=(1 \times 4.5+2 \times$ $4.5) / 3 \times 100 / 5=90$ Jadi untuk skor yang diperoleh untuk penggabungan teori dan praktek siklus 1 adalah sebesar 90 .

Hasil pengamatan dan pengukuran tersebut menunjukkan bahwa menyusun RPP dan melakukan simulasi pembelajaran percobaan sesuai dengan langkahlangkah pada RPP untuk mencapai tujuan pembelajaran masih rendah. Untuk itu perlu dilakukan tindakan perbaikan pembelajaran selanjutnya pada perbaikan pembelajaran siklus berikutnya.

\section{Siklus II}

Perbaikan pembelajaran dilakukan berdasarkan hasil refleksi dari siklus I. Perbaikan pembelajaran dilakukan sesuai dengan RPP dan langkah-langkah pembelajaran yang telah dibuat. Pelaksanaan perbaikan pembelajaran dan percobaan dilaksanakan melalui Video simulasi pembelajaran Siklus 2 mata pelajaran IPA pada tema Bagian Tumbuhtumbuhan dan fungsinya. Berdasarkan video simulasi yang telah dilakukan oleh Peneliti dan Mahasiswa, Validator melakukan review dan penilaian melalui instrumen APS-1 dan APS-2 pada RPP dan Video simulasi untuk siklus II.

Adapun hasil riview terhadap RPP dan Video Percobaan pada siklus II adalah sebagai berikut : Alat Penilaian Simulasi PKP 1 (APS-PKP 1)-Lembar Penilaian Simulasi Merencanakan Perbaikan Pembelajaran Petunjuk: Baca dengan cermat rencana perbaikan pembelajaran yang akan digunakan oleh guru / mahasiswa ketika mengajar. Kemudian, nilailah semua aspek yang terdapat dalam rencana tersebut dengan menggunakan butir penilaian di bawah ini. Alat Penilaian Simulasi 2 (APS-2)-Lembar Penilaian Simulasi Melaksanakan Perbaikan Pembelajaran Praktikum Petunjuk: Amatilah dengan cermat video pembelajaran. Pusatkanlah perhatian Anda pada kemampuan guru dalam mengelola pembelajaran serta dampaknya pada diri siswa. Nilailah kemampuan guru tersebut dengan menggunakan butir-butir penilaian berikut. Penggabungan APS PKP1 + APS PKP2 $=(1 \times$ APS PKP1 $+2 x$ APS PKP2)/3 x 100/5Skor Perolehan penggabungan antara teori dan praktek $=(1 \times 4+2 \times 4.7) / 3 \times 100 / 5=$ 96.

Hasil pengukuran keberhasilan tindakan perbaikan pembelajaran siklus 2, yakni melalui penilaian RPP perbaikan pembelajaran siklus 2 dan video praktek simulasi pembelajaran 
percobaan siklus 2 telah dilakukan oleh Validator menggunakan instrumen APS-1 dan APS-2. Hasil penilaian terhadap RPP siklus 2 melalui instrumen APS-1 mendapatkan skor sebesar 4,8 dan hasil penilaian terhadap video simulasi pembelajaran percobaan siklus 2 melalui instrumen APS-2 mendapat skor sebesar 4,8. Kemudian untuk penggabungan APS-PKP $1+$ APS-PKP 2 yang dihitung melalui rumus $(1 \times$ APS PKP1 $+2 \times$ APS PKP2 $) / 3 \times 100 / 5=(1 \times 4+2 \times 4.7) / 3$ $\mathrm{x} 100 / 5=96$. Jadi untuk skor yang diperoleh untuk penggabungan teori dan praktek siklus 2 adalah sebesar 96. Hasil pengamatan dan pengukuran tersebut pada tabel 4.8 menunjukkan bahwa perbaikan pembelajaran dan percobaan sesuai dengan RPP dan langkah-langkah yang sesuai dengan yang direncanakan dan melakukan video simulasi pembelajaran percobaan sesuai dengan tujuan yang dicapai serta terlaksana dengan baik sehingga tindakan perbaikan dihentikan sampai siklus 2 .

Berdasarkan penilaian APS1(RPP) dan APS-P2 (Video Praktek), bahwa perbaikan pembelajaran siklus 2 sudah mengalami peningkatan dari siklus sebelumnya. Perubahan pembelajaran dan praktikum telah dilakukan dengan dengan baik dan sesuai dengan Lembar Kerja Percobaan Untuk mendapatkan pembelajaran dan percobaan yang menarik dalam pembelajaran IPA perlu pemusatan perhatian terhadap objek yang dipelajari. Dalam penelitian ini mengungkapkan tentang perbaikan pembelajaran dan percobaan IPA pada tema Bagian Tumbuh-tumbuhan dan fungsinya dengan menggunakan alat dan bahan disekitar siswa. Temuan perbaikan pembelajaran dan percobaan dari simulasi yang dilakukan pada siklus I dan siklus II dalam menentukan dan merencanakan pembelajaran telah mengalami perubahan dari siklus $1 \mathrm{ke}$ siklus 2.

Adanya perubahan dan peningkatan dari siklus I ke siklus II, terlihat dari perolehan skor pada RPP 1 didapatkan skor 4,5 sedangkan pada RPP 2 ada kenaikan skor yaitu 3. Hal ini juga terlihat pada perolehan skor video perbaikan siklus 1 didapatkan skor 4,6 sedangkan pada video perbaikan siklus 2 ada kenaikan skor yaitu 4,8. Sedangkan untuk total skor penggabungan antara RPP + Video pada siklus 1 adalah sebesar 90 sedangkan untuk skor penggabungan antara RPP + Video pada siklus 2 adalah sebesar 96. Berdasarkan hasil pengamatan dan pengukuran keseluruhan perbaikan pembelajaran (Tabel 4.4) dapat dinyatakan bahwa perbaikan pembelajaran dengan menggunakan Bupena pada Percobaan tema Bagian Tumbuhtumbuhan dan fungsinya efektif untuk digunakan dalam pembelajaran IPA di kelas IV SD Negeri 068007 Medan Tuntungan Tahun Pelajaran 2021/2022. 


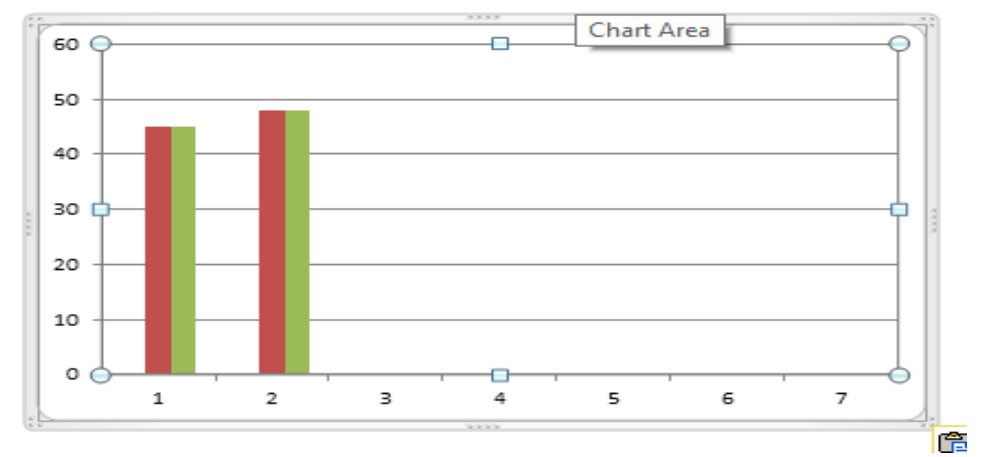

\section{Grafik 1. Perbandingan Penilaian Siklus I dan Siklus II}

Berdasarkan grafik diatas, pada siklus 2 mengalami peningkatan pelaksanaan pembelajaran dan menjadi 4,8. Kemudian untuk skor percobaan pada siklus 2 mengalami video simulasi pada siklus 1 adalah peningkatan dari siklus 1. Untuk skor sebesar 4,6 dan pada siklus 2 RPP pada siklus 1 hanya mengalami peningkatan menjadi 4,8 . mendapatkan skor 4,6 sedangkan

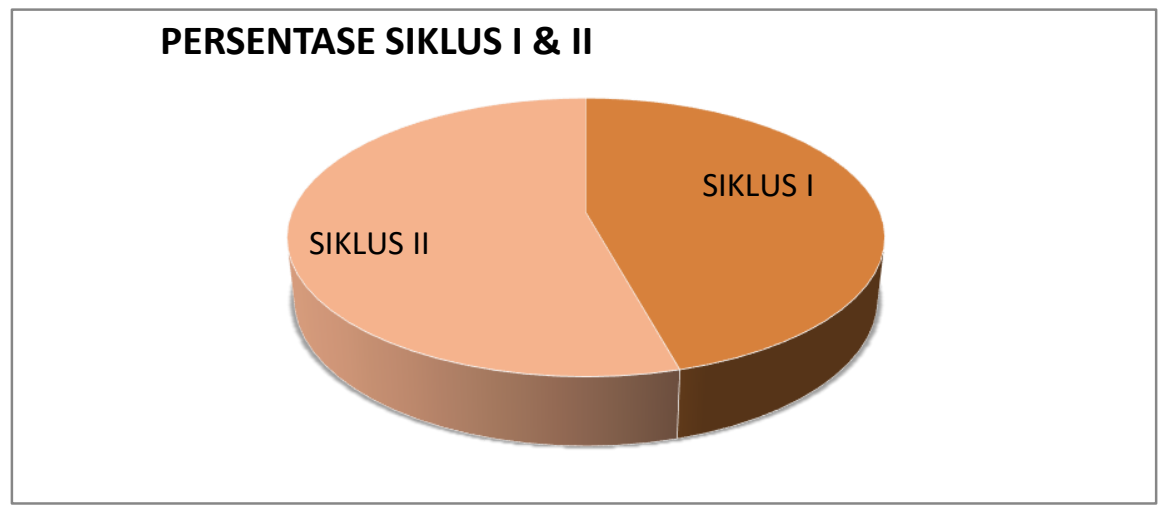

\section{Grafik 2. Persentase Siklus I Dan Siklus II}

Berdasarkan grafik diatas dapat ditarik kesimpulan bahwa "Telah terjadi perbaikan pembelajaran dan percobaan pada mata pelajaran IPA pada tema Bagian Tumbuh-tumbuhan dan fungsinya di kelas IV SD Negeri 068007 Medan Tuntungan Tahun Pelajaran 2021/2022." Hal ini disebabkan karena penggunaan Bupena dalam siklus 2 lebih jelas dan mudah dipahami oleh siswa.

\section{Pembahasan}

Perbaikan pembelajaran IPA yang dilakukan dapat menumbuhkan minat siswa dalam pembelajaran dan percobaan yang nantinya akan berdampak baik bagi hasil belajar yang diperoleh siswa. Pembelajaran dan percobaan yang baik adalah pembelajaran yang melibatkan keaktifan siswa didalam kelas, artinya pembelajaran yang dilakukan tidak hanya berpusat pada guru saja, namun siswa juga berperan aktif didalamnya. 
Dengan menggunakan Bupena dengan melakukan percobaan yang digunakan, dapat mempermudah guru dalam menyampaikan materi pembelajaran. Para siswa juga menjadi lebih aktif dan bersemangat dalam mengikuti proses pembelajaran dan kegiatan percobaan. Dengan menggunakkan Bupena, siswa dapat melihat, memegang dan mengamati langsung objek yang menjadi fokus utama dalam pembelajaran yaitu tumbuh-tumbuhan. Pada dasarnya, selama ini mereka hanya mengenal tumbuhan saja, namun tidak mengerti bahwasanya banyak informasi yang belum siswa ketahui mengenai fungsi dan manfaat tumbuh-tumbuhan tersebut.

Dalam pembelajaran dan kegiatan percobaan, guru harus cerdas dalam memilih media dan alat percobaan yang dapat memudahkan siswa dalam menerima informasi baru melalui media pembelajaran. Guru juga harus bijak dalam menggunakan media pembelajaran, artinya guru bisa mengkombinasikan media pembelajaran dengan metode atau model mengajar yang sesuai dengan materi yang diajarkan. Pada akhirnya, apabila guru dapat memilih media yang tepat dalam pembelajaran, akan berdampak baik bagi hasil belajar siswa.

Dalam membelajarkan IPA, seorang guru juga dapat memanfaatkan lingkungan sekitar sebagai media pembelajaran. Dengan demikian siswa dapat mengalami pembelajaran secara langsung dan pembelajaran tidak bersifat imajinatif saja.

\section{SIMPULAN}

Berdasarkan hasil penelitian dan pembahasan yang telah dipaparkan, maka dapat ditarik kesimpulan bahwa "Terjadi Perbaikan Pembelajaran dengan Menggunakan Bupena pada Percobaan tema Bagian Tumbuh-tumbuhan dan fungsinya di SD Negeri 068007 Medan Tuntungan Tahun Pelajaran 2021/2022”.

\section{DAFTAR RUJUKAN}

Akbar Sa'dun. 2013. Instrumen Perangkat Pembelajaran. Bandung: Remaja

Asih Widi dan Eka Sulistyowati. 2015. Metodologi

Pembelajaran IPA. Jakarta: Bumi Aksara.

Syaiful Bahri dan Aswan. 2015. Strategi Belajar Mengajar. Jakarta: Rineka Cipta.

Hanafiah, Kemas Ali. 2016. Rancangan Percobaan. Jakarta: Rajawali Pers.

Hunaepi, Taufik dkk. 2014. Sains Teknologi Masyarakat. Mataram: Duta Pustaka Ilmu.

Irene, Gunanto dkk. 2016. Buku Penilaian Bupena. Jakarta: Erlangga.

Nana, Syaodih. 2015. Metode Penelitian Pendidikan.

Bandung: Remaja Rosdakarya

Permatasari, Indah, dkk. 2012. Penuntun Praktikum Botani. Pekanbaru : FAPERTAPET UIN Suska Riau.

Ridwan Abdullah, Sudiran dkk. 2018. Penelitian Pendidikan. 
Hotma Tiolina Siregar,Taty Sukanti Halawa : Perbaikan Pembelajaran ...

Tanggerang: Tira Smart.

Samidi \& Istarani. 2016. Kompetensi

\& Profesionalisme Guru Ilmu

Pengetahuan Alam (IPA) Dan

Matematika. Medan: Larispa

Indonesia

Siregar Syofian. 2014. Statistik

Parametrik untuk Penelitian

Kuantitatif. Jakarta : Bumi

Aksara.

Sudaryono. 2017. Metodologi

Penelitian. Depok : Rajawali

Pers

Wardhani, I G A K. dkk. 2017.

Pemantapan Kemampuan

Profesional. Jakarta:

Universitas Terbuka. 